\title{
The immunological and long-term atopic outcome of infants born to women following a milk-free diet during late pregnancy and lactation: a pilot study
}

\author{
BY JULIE A. LOVEGROVE, SHELAGH M. HAMPTON AND JANE B. MORGAN \\ Division of Biomedical Research, School of Biological Sciences, University of Surrey, Guildford \\ GU2 $5 X H$, Surrey
}

(Received 22 October 1992 - Revised 18 February 1993 - Accepted I April 1993)

\begin{abstract}
Infants born to atopic parents have been found to be at high risk of allergy development. The present study investigated the effect of a maternal milk-free diet during late pregnancy and lactation on the immune response and allergy incidence in at-risk and control infants. Atopic mothers were randomly allocated into an intervention group $(n 12)$ or an unrestricted-diet group $(n 14)$ and compared with nonatopic mothers following an unrestricted diet $(n 12)$. The intervention involved a maternal milk-free diet during late pregnancy and lactation. Infants were followed up for 18 months postnatally. A significant fall in maternal serum $\beta$-lactoglobulin $(\beta$-Lg)-immunoglobulin $G(I g G)$ antibody levels $(P<0.05)$ was observed after a 7-week milk-exclusion diet. In maternal and cord serum samples the levels of $\beta$ - $\mathbf{L g}$-IgG and $\alpha$-casein-IgG antibodies were significantly correlated $(r 0.89, P<0.0001$ and $r 0.71, P<0.001$ respectively). Higher levels of $\beta$-Lg-IgG $(P<0.05)$ were observed in the cord serum samples compared with paired maternal serum samples. Single-blind allergy assessment by a paediatrician at 12 and 18 months showed that the infants born in the non-atopic group had a significantly lower allergy incidence compared with the infants born in the atopic group following an unrestricted diet $(P<0.008$ and $P<$ 0.02 respectively). The allergy incidence in the infants born in the atopic diet group was significantly lower compared with that of the atopic group following an unrestricted diet $(P<0.04)$. It was observed that the atopic nature of the parents significantly affected the allergy incidence in their children. A trend towards a beneficial effect of a maternal milk-free diet during late pregnancy and lactation was also observed in infants born to atopic parents.
\end{abstract}

Milk-free diet: Infant allergy: Immune response.

The elimination of an offending food or foods from the mother's diet has been recognized as an important way of alleviating allergy symptoms in breast-fed infants. As far back as 1918, Talbot (Talbot, 1918) reported that the removal of chocolate from a mother's diet eliminated her infant's eczema. Many other studies have reported the benefit of removing foods, especially milk and eggs, from maternal diets during breast-feeding as a means of reducing their infants' eczema (Jakobsson \& Lindberg, 1978; Cant et al. 1985).

More recently intervention studies have been used as a prophylactic technique to prevent allergy development in infants. The benefit of a maternal exclusion diet during pregnancy, lactation or both, has been investigated for a number of years. Studies performed by Chandra et al. (1986) and Zeiger et al. (1989) reported that avoidance of common dietary allergens during pregnancy and lactation enhanced the benefit of exclusive breast-feeding on the incidence of atopic eczema in at risk infants (those infants with parents or siblings with allergy). The Swedish group (Fälth-Magnusson \& Kjellman, 1987; Fälth-Magnusson et al. 1987, 1988; Lilja et al. 1988, 1989) looked at the benefit of maternal dietary exclusion of milk and eggs during the last trimester of pregnancy. It was reported that the incidence 
of infant allergy development, and infant serum antibody levels, were unaffected by the mother's diet, although maternal serum antibody levels were reported to be affected by the levels of ingested proteins.

The results of these studies suggested that dietary intervention during lactation rather than during pregnancy should be of more benefit to the at-risk infant. This hypothesis was supported by the results from studies by Chandra et al. (1989) and Hattevig et al. (1989, 1990). Both groups concluded that maternal dietary intervention during the period of breast-feeding afforded a significant reduction in the incidence of atopic eczema in at-risk infants. Lower milk-specific antibody levels were also found in the intervention group compared with the other two groups at 6 months (Hattevig et al. 1990).

From these studies it has been concluded that infants of parents with a history of allergic disease, or infants with a sibling with food allergy, could benefit from a maternal elimination diet during lactation, although it has been suggested that the reduced allergy incidence may reflect a delayed onset of allergy symptoms, which could become apparent later in life, rather than a prevention (Aberg et al. 1989).

The aim of the present study was to determine the effect of a maternal milk-free diet during late pregnancy and lactation on the allergy development and immune response of at-risk infants compared with normal and at-risk infants whose mothers were following an unrestricted diet. A hypoallergenic formula, Peptijunior (Cow \& Gate, Trowbridge, Wilts), was used as a milk alternative for the mother and infants. The transfer of cows' milk $\beta$ lactoglobulin $(\beta$ - Lg)- and $\alpha$-casein $(\alpha$-cas)-specific antibodies and $\beta$ - $\mathrm{Lg}$ from mother to infant was determined, in addition to the immune response of the mother during compliance to a milk-free diet.

\section{MATERIALS AND METHODS}

\section{Subjects}

Women were approached by the investigator at an antenatal clinic at St Luke's Hospital, Guildford, Surrey, at 30 weeks gestation, between May 1988 and November 1989. The study protocol was explained to all women, and those who showed an interest were subsequently visited at home. All women agreeing to participate in the study read and signed an informed-consent form. Each woman was given an allergy and environmental questionnaire: this included questions regarding the allergy incidence of the subject and her immediate family, medication taken, if any, date of birth, height and prepregnancy weight. Women who had an allergy themselves, or whose partner had an allergy, were defined as atopic. The types of allergies that were suffered by the atopic subjects included eczema, asthma, hayfever and atopic dermatitis. Symptoms that were anecdotal were not accepted; only those subjects who suffered from allergies that had been diagnosed by a clinician were accepted as atopic. These mothers were randomly allocated into either a diet or unrestricted-diet group. The non-atopic group also followed an unrestricted diet.

\section{Interventions}

\section{Prophylaxis-group diet}

From approximately 36 weeks gestation and during breast-feeding the women in the prophylactic-treated group were instructed to avoid totally all milk and dairy products. As a milk alternative, a hypoallergenic, complete infant formula, Peptijunior (Cow \& Gate, Trowbridge, Wilts), was given to the mothers to consume as required. If breast-feeding was supplemented or stopped this whey hydrolysate was offered to the infants. In addition to this, $1000 \mathrm{mg} \mathrm{Ca}$ supplement was given daily to each woman in the form of Calcichew (Shire Pharmaceuticals Ltd., Andover, Hants.), a supplement derived from $\mathrm{CaCO}_{3}$. 
The women who were following the diet were initially given information regarding the dietary changes required, food lists, recipes and product sources. During the period of dietary compliance the subjects were frequently contacted by the investigator to ensure that they were coping with the restriction and receiving adequate nutrients.

On admittance to hospital the nurses were informed about the maternal dietary restriction and the necessity not to give the babies 'top-up' bottle feeds.

\section{Control-group diet}

Pregnant and lactating control group women were encouraged to follow standard diets for pregnancy and lactation. On analysis of the women's diets it was found that all the women in the control group consumed a minimum of $500 \mathrm{ml}$ cows' milk daily. No recommendation was given to these subjects regarding cows' milk intake.

\section{Infant feeding}

All mothers were encouraged to practise exclusive breast-feeding for as long as possible and preferably for 6 months. Solid feeding was discouraged until 3 months and started with baby rice and vegetables. In all groups, provision of cows' milk to the infant was discouraged until at lest 6 months or longer. Other weaning practices were performed at the mother's discretion.

\section{Samples required}

A $10 \mathrm{ml}$ venous blood sample was taken from the mothers following the prophylaxis diet and those on the control diet, at 34 weeks and 36-38 weeks gestation respectively. Venous blood samples were taken from the atopic-diet group at 1 week and at 3,6 and 12 months postpartum, or until they ended their dietary compliance. An unstimulated saliva sample was also required from all subjects at approximately the same time as blood was sampled.

Heel prick blood samples were taken from the infants by using an autolet (Owen Mumford Ltd, Medical Division, Brookhill, Oxon.) at 1 week and at 3,6 and 12 months postpartum. The blood was collected into a $200 \mu$ Eppendorf microcentrifuge tube (Merck Ltd., Lutterworth, Leicestershire), and spun in an Eppendorf microcentrifuge for $5 \mathrm{~min}$; the serum was then subsampled and stored at $-20^{\circ}$ until required for analysis. Infant saliva samples were also collected by the mother once weekly for the first month, once monthly for the next 5 months and then at 12 and 18 months.

\section{Biochemical analysis}

Quantification of total $\beta$-Lg-immunoglobulin $\mathrm{G}$ (IgG) and $\alpha$-cas-IgG in maternal, cord and infant serum samples was determined using an indirect ELISA previously described by Hampton et al. (1989) and Lovegrove et al. (1989) respectively. Circulating $\beta$-Lg was also quantified in the maternal and cord serum samples using a sandwich ELISA (Lovegrove et al. 1993).

\section{Assignment of patients}

$$
\text { Study design }
$$

The pregnant women selected for the study were designated as atopic or non-atopic, identified by an allergy and environmental questionnaire which had been perviously validated (Lovegrove, 1991). The atopic group was randomly allocated into the prophylaxis group or the control group. Before changing their diet, all women assigned to the prophylaxis group ingested normal amounts of cows' milk and dairy products.

\section{Maternal compliance}

In order to evaluate the compliance with the dietary regimen, the women were asked to complete a $7 \mathrm{~d}$ weighed food inventory. This was used to quantify any milk protein which 
may have been inadvertently consumed. The women following the restricted diet were asked to record any times of dietary non-compliance. These occasions were considered when assessing the biochemical analysis of the samples.

\section{Physical examination}

All children were examined at 6,12 and 18 months of age. A 'blind' physical examination, was performed by Dr Mir, a paediatrician from St Luke's Hospital, who was unaware to which group the infants' mothers were assigned. The allergy incidence was defined as the occurrence of clinically-diagnosed atopic eczema, the severity of which was scored on a scale of 1-3 with the least severe as 1 . The severity-scoring system was used routinely and based on the area covered by the eczema and the degree of skin irritation. The allergy incidence at 6,12 and 18 months for the infants born to the mothers in the three groups was recorded, in addition to the mean severity score.

\section{Statistical analysis}

A random fixed model analysis of variance, paired and unpaired Student's $t$ test, Fisher's exact probability test and Pearson's correlation (Sokal \& Rohlf, 1969) were performed where appropriate.

\section{Ethical considerations}

Due to the lack of adequate data on the effect of a maternal milk-free diet on infant's immune responses in early life, the analysis of infant samples was of prime importance. Infant saliva samples were taken to determine mucosal immune development because the collection method used was non-invasive and easy to perform with minimal discomfort to the infant and mother. Serum samples were also taken to monitor the passively-transferred maternal immunity and the developing infant circulatory response, which have not been investigated in comparable studies. The study received ethical approval from the South West Surrey Regional Health Authority on 7 June 1988.

\section{RESULTS}

Subjects

Of the ninety-six women approached, forty-four (45\%) initially agreed to take part in the study; however, six $(14 \%)$ of the forty-four subjects did not complete the study for various reasons, which resulted in a final number of thirty-eight women. Finally there were fourteen atopic and twelve non-atopic mothers following an unrestricted diet and twelve atopic mothers following the restricted diet. All women were healthy and had uncomplicated pregnancies. Table 1 shows the data from the questionnaire for the women in the three groups. The mean age for the women was 31 (SD 6) years, with the three groups having the same mean age.

The allergies suffered by the atopic women in the unrestricted-diet group and intervention group were similar, with a mean period of suffering reported as 15 (SD 7) years and 19 (SD 9) years respectively, as shown in Table 1. Within the intervention group two of the women did not report suffering from any known allergies. The allergy incidence in the families of the atopic, non-atopic and atopic-diet groups were eleven, eight and eleven respectively. The allergy incidence of the women's children, partners and the partners' family were comparable in the two atopic groups but lower in the non-atopic group.

\section{Dietary compliance}

It was observed that the mean nutrient intakes of the three groups of women were within the UK dietary reference values (DRV; Department of Health, 1991) and not significantly 
Table 1. Details of the subjects recruited on the long-term dietary intervention study

(Mean values, standard deviations and ranges)

\begin{tabular}{|c|c|c|c|c|c|c|c|c|c|}
\hline \multirow[t]{2}{*}{$\begin{array}{l}\text { Study group ... } \\
n \ldots\end{array}$} & \multicolumn{3}{|c|}{$\begin{array}{c}\text { Atopic } \\
14\end{array}$} & \multicolumn{3}{|c|}{$\begin{array}{c}\text { Non-atopic } \\
12\end{array}$} & \multicolumn{3}{|c|}{$\begin{array}{c}\text { Atopic-diet } \\
12\end{array}$} \\
\hline & Mean & SD & Range & Mean & SD & Range & Mean & SD & Range \\
\hline Age (years) & 31 & 2 & $27-34$ & 31 & 3 & $25-33$ & 31 & 5 & $21-36$ \\
\hline Parity & 1 & 1 & $0-2$ & 1 & 1 & $0-2$ & 1 & 1 & $0-2$ \\
\hline Allergy incidence & 12 & & & - & & & 10 & & \\
\hline Period of symptoms (years) & 15 & 7 & Birth-1 & - & & & 19 & 9 & Birth-1 \\
\hline
\end{tabular}

Table 2. Details of the infants born to the subjects of the long-term intervention study, with allergy incidence and severity assessed blind by a paediatrician $\dagger$

(Mean values, standard deviations and ranges)

\begin{tabular}{|c|c|c|c|c|c|c|c|c|c|}
\hline \multirow[t]{2}{*}{$\begin{array}{l}\text { Study group... } \\
n \ldots\end{array}$} & \multicolumn{3}{|c|}{$\begin{array}{c}\text { Atopic } \\
14\end{array}$} & \multicolumn{3}{|c|}{$\begin{array}{c}\text { Non-atopic } \\
13 \S\end{array}$} & \multicolumn{3}{|c|}{$\begin{array}{c}\text { Atopic-diet } \$ \\
12\end{array}$} \\
\hline & Mean & SD & Range & Mean & $\mathrm{SD}$ & Range & Mean & SD & Range \\
\hline No. of male infants & 10 & & & 6 & & & 4 & & \\
\hline No. of female infants & 4 & & & 7 & & & 8 & & \\
\hline $\mathrm{Wt}(\mathrm{kg})$ & $3 \cdot 7$ & $0 \cdot 5$ & $3 \cdot 1-4 \cdot 7$ & $3 \cdot 2$ & 0.3 & $2 \cdot 8-3 \cdot 7$ & 3.6 & $0 \cdot 5$ & $3 \cdot 1-4 \cdot 5$ \\
\hline \multicolumn{10}{|l|}{6 months } \\
\hline Allergy incidence & 4 & & & 2 & & & 3 & & \\
\hline Severity & 2 & 1 & $1-3$ & 2 & 1 & $2-3$ & 2 & 1 & $1-3$ \\
\hline \multicolumn{10}{|l|}{12 months } \\
\hline Allergy incidence & 8 & & & $2 * * *$ & & & $5(2)$ & & \\
\hline Severity & 2 & 1 & $1-3$ & 1 & 1 & 1 & $2(1)$ & $1(1)$ & $1-3(1-2)$ \\
\hline \multicolumn{10}{|l|}{18 months } \\
\hline Allergy & 7 & & & $2 * *$ & & & $4(1)^{*}$ & & \\
\hline Severity & 2 & 1 & $1--3$ & 1 & 0 & 1 & $1(2)$ & $1(0)$ & $1-2(2)$ \\
\hline
\end{tabular}

Mean values were significantly different from those for the atopic group: ${ }^{*} P<0.04,{ }^{*} P<0.02, * * * P<0 \cdot 008$.

$\dagger$ For details of subjects and procedures, see pp. 224-226 and Table 1.

$\$$ Data from the atopic-diet group excluding three infants who inadvertently received at least one feed of commercial infant formula derived from cows' milk shortly after delivery are shown in parentheses.

$\S$ Included one set of twins.

different from each other, except for the calculated polyunsaturated:saturated fat (P:S) ratio. The mean values for the atopic, atopic-diet and non-atopic groups were 0.2 (SD 0.1 ), 0.5 (SD 0.2$)$ and $0.2($ SD $0 \cdot 1)$ respectively. The atopic-diet group had a significantly higher $(P<0.01)$ mean $\mathrm{P}: \mathrm{S}$ ratio compared with the other two groups.

Women recorded any incidence of dietary non-compliance, which more often than not occurred during their hospital stay. Usually cows' milk-protein ingestion was in the form of cakes, pies, biscuits and margarine. Only one woman, in the atopic-diet group, admitted the ingestion of whole cows' milk on a single occasion during her stay in hospital.

\section{Infants}

All the infants were born within $40-44$ weeks gestation. One pair of non-identical twins were born to a mother in the non-atopic group. There was no significant difference between the mean birth weights of the infants within the three groups, although the atopic infants 
had a higher mean birth weight compared with the non-atopic infants, as shown in Table 2. The male:female ratios within the atopic, non-atopic and atopic-diet groups were $10: 4$, $6: 7$ and $4: 8$ respectively.

Allergy assessment was completed blind by the same paediatrician at 6,12 and 18 months postpartum. The allergy incidence and the mean severity scores are shown in Table 2 . A Fishers exact probability test (Sokal \& Rohlf, 1969) was performed on the data crosstabulating the maternal groups with the allergy incidence. A significant difference of $P<0.008$ and $P<0.02$ was found between the allergy incidence in the infants born to the mothers in the atopic group who followed an unrestricted diet compared with the mothers assigned to the non-atopic group at 12 and 18 months respectively. It was reported that the two infants who went to the special care unit were both given a cows' milk formula on at least one occasion. Another infant in the atopic-diet group also received cows' milk formula on days 7 and 8 postpartum. Peptijunior was offered to the infant but it was not tolerated. These three infants who were in the atopic-diet group were diagnosed as having allergies. When the data relating to these three infants was removed from the total allergy incidence data for the atopic-diet group, there was found to be a significant difference $(P<0.04)$ in the allergy incidence at 18 months of age between the infants born to atopic women who followed an unrestricted diet compared with atopic women who followed a milk-free diet.

\section{Infant feeding}

All mothers attempted to breast-feed their infants; the minimum time of breast-feeding was 1 month, although the majority of women breast-fed until 4 months. The mean duration of breast-feeding in the atopic-diet group was longer (12 (SD 3) months) although not significantly different from the other two groups (9 (SD 4) months and 9 (SD 3) months for the atopic and non-atopic groups respectively). Due to the natural resistance of the mothers in the atopic-diet group to the introduction of cows' milk into their infants' diet, the time of introduction of cows' milk formula, cows' milk and yoghurt was significantly later for the women in this group compared with the non-atopic group $(P<0.05)$. The introduction of the other foods was not significantly different between the three groups, as shown in Table 3.

\section{Whey-protein-hydrolysate formula (Peptijunior)}

Peptijunior was used routinely by five of the women in the intervention group as a cows' milk alternative. Peptijunior was offered to six of the infants born to the mothers in the intervention group, and used routinely as a milk feed for four of these infants.

\section{Maternal and cord serum sample analysis}

The maternal and cord serum $\beta$-Lg-IgG, $\alpha$-cas-IgG and $\beta$-Lg levels are shown in Fig. 1 . Detectable levels of $\beta$ - $\mathrm{Lg}-\operatorname{IgG}$ and $\alpha$-cas-IgG were found in all the serum samples analysed. The wide ranges reflect the large individual variation. The $\alpha$-cas-IgG antibody levels were consistently lower in all the serum samples analysed, compared with the $\beta$-Lg-IgG antibody levels, although this difference was not found to be significant in any group. A significant correlation was found between the $\beta$ - $\mathrm{Lg}-\operatorname{IgG}$ and $\alpha$-cas-IgG antibody levels in the maternal and cord serum samples $(r 0.89, P<0.0001$ and $r 0.71, P<0.001$ respectively).

The levels of $\beta$ - $\mathrm{Lg}-\mathrm{IgG}$ and $\alpha$-cas-IgG were higher in the cord serum samples compared with the maternal serum samples, excluding the $\alpha$-cas-IgG antibody levels in the atopic group. A significant correlation was found between the $\beta$ - $\mathrm{Lg}-\mathrm{IgG}$ level in the maternal and cord serum samples $(r 0.89, P<0 \cdot 0001)$, and between the $\alpha$-cas-IgG antibody levels in the maternal and cord serum $(r 0.97, P<0.0001)$. 
Table 3. Postpartum introduction of foods into the diet of the infants born to the atopic, non-atopic and atopic-diet group +

(Mean values, standard deviations and ranges)

\begin{tabular}{|c|c|c|c|c|c|c|c|c|c|}
\hline \multirow[t]{2}{*}{$\begin{array}{l}\text { Study group... } \\
n \ldots\end{array}$} & \multicolumn{3}{|c|}{$\underset{14}{\text { Atopic }}$} & \multicolumn{3}{|c|}{$\begin{array}{c}\text { Non-atopic } \\
13 \S\end{array}$} & \multicolumn{3}{|c|}{$\begin{array}{c}\text { Atopic-diet } \\
12\end{array}$} \\
\hline & Mean & SD & Range & Mean & SD & Range & Mean & $\mathrm{SD}$ & Range \\
\hline $\begin{array}{l}\text { Duration of breast-feeding } \\
\text { (months) } \\
\text { Age at food introduction } \\
\text { (months) }\end{array}$ & 9 & 4 & $1-14$ & 9 & 3 & $2-13$ & 12 & 3 & $7-15$ \\
\hline Bottle-feeding & $1^{*}$ & 1 & $0-2$ & 3 & 2 & $1-6$ & $5+t+$ & 2 & $2-8$ \\
\hline $\begin{array}{l}\text { Cow's milk, yoghurt and } \\
\text { cheese }\end{array}$ & 10 & 2 & $6-12$ & 8 & 3 & $6-12$ & $12 *$ & 4 & $6-18$ \\
\hline
\end{tabular}

Mean values were significantly different from those of the non-atopic group: ${ }^{*} P<0.05$.

Mean value was significantly different from that of the atopic group: $\dagger+\dagger P<0.005$.

$\ddagger$ For details of subjects and procedures, see pp. 224-226 and Table 1.

$\S$ Included one set of twins.

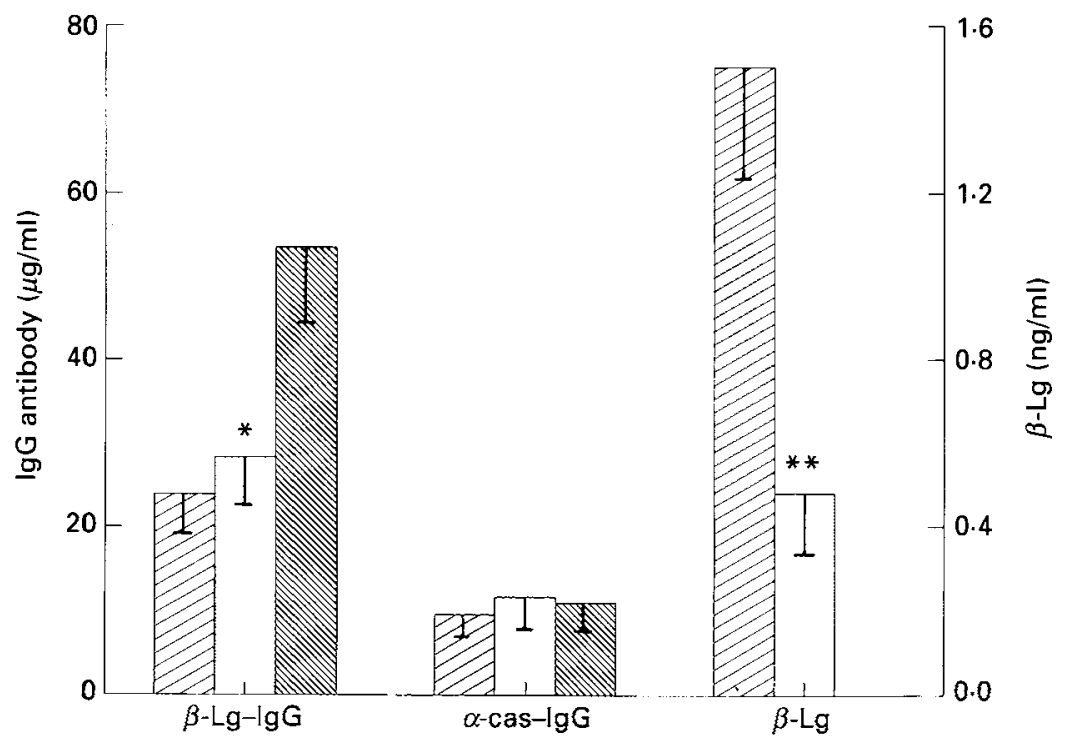

Fig. 1. Mean levels of $\beta$-lactoglobulin ( $\beta$-Lg)-immunoglobulin $\mathrm{G}$ (IgG), $\alpha$-casein $(\alpha$-cas)--IgG and $\beta$ - $\mathrm{Lg}$ in maternal $(\bigotimes)$, cord $(\square)$ and infant $(\mathbb{\nabla})$ serum. Values are means with their standard errors represented by vertical bars. Mean values were significantly different from those for maternal serum ${ }^{*} P<0.05,{ }^{* *} P<0 \cdot 01$. For details of subjects and procedures, see pp. 224-226 and Table 1.

The levels of $\beta$-Lg-IgG antibodies within the serum samples of the three groups of women were comparable. However, the levels of $\alpha$-cas-IgG antibodies were found to be highest in the atopic-diet group and lowest in the unrestricted atopic group. On further examination of the individual values, it was observed that one individual in the atopic-diet group had dramatically elevated antibody levels. The antibody levels in the three groups were not significantly different. 


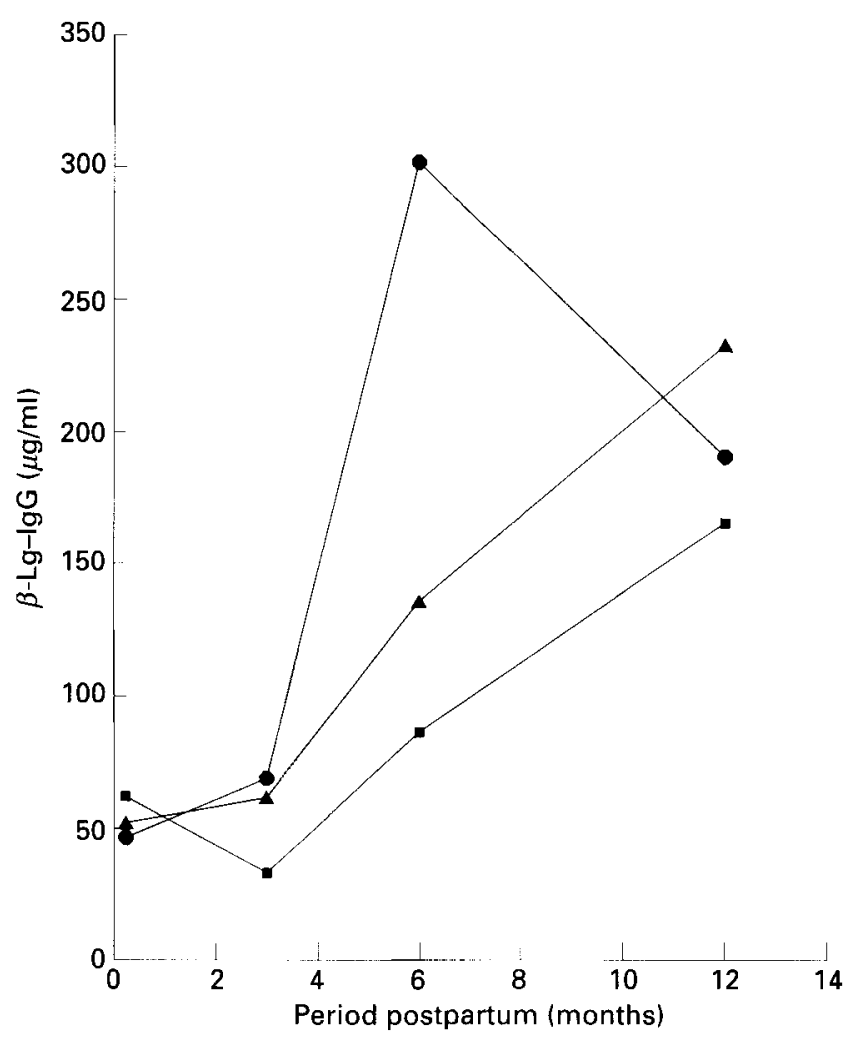

Fig. 2. Mean $\beta$-lactoglobulin ( $\beta$-Lg)-immunoglobulin $\mathrm{G}$ (IgG) antibody levels in serum samples from infants born to women in the atopic $(\boldsymbol{O})(n$ 14), non-atopic $(\boldsymbol{A})(n$ 13) and atopic-diet $(\boldsymbol{\square})(n$ 12) groups during the 12-month period postpartum. The mean SD was $124 \%$ of the mean $(64-248 \%)$. For details of subjects and procedures, see pp. 224-226 and Table 1.

Circulating antigenically-intact $\beta$ - $\mathrm{Lg}$ was observed in 64,58 and $33 \%$ of the maternal serum samples and in 43,25 and $8 \%$ of the cord serum samples in the atopic, non-atopic and atopic-diet groups respectively. The $\beta$ - $\mathrm{Lg}$ antigen levels were found to be significantly lower in the maternal serum samples compared with the cord serum samples $(P<0.01)$. The three women in the atopic-diet group who had detectable $\beta$-Lg levels in their serum at 1 week postnatally admitted the ingestion of cows' milk protein during their stay in hospital; however, no detectable $\beta$-Lg was found within the maternal or cord serum samples of the other women within this group.

Effect of the intervention diet on serum $\beta-\operatorname{Lg}-\operatorname{Ig} G$ and $\alpha$-cas-IgG antibody levels The mean levels of $\beta$-Lg-IgG and $\alpha$-cas-IgG in maternal serum samples before commencing the milk-free diet were 123.4 (SD 265.6) and 25.8 (SD 56.3) $\mu \mathrm{g} / \mathrm{ml}$ respectively, and after the diet for a period of 7 weeks ( 6 weeks before and 1 week after delivery) the $\beta$-Lg-IgG and $\alpha$-cas-IgG antibody levels were 96.6 (SD 226.8) and 15.4 (SD 29.4 ) $\mu \mathrm{g} / \mathrm{ml}$ respectively. The $\beta$ - Lg-IgG and $\alpha$-cas $-\mathrm{IgG}$ antibody levels were found to decrease during the diet period. This was found to be significant for the $\beta$ - Lg-IgG antibody levels $(P<0 \cdot 05)$. The reduction was found to be greater in the individuals with an initially high antibody level. The $\beta$ $\mathrm{Lg}-\mathrm{IgG}$ and $\alpha$-cas-IgG antibody levels decrease over the whole period of dietary intervention, with the greatest difference being in the initial 7-week period. 


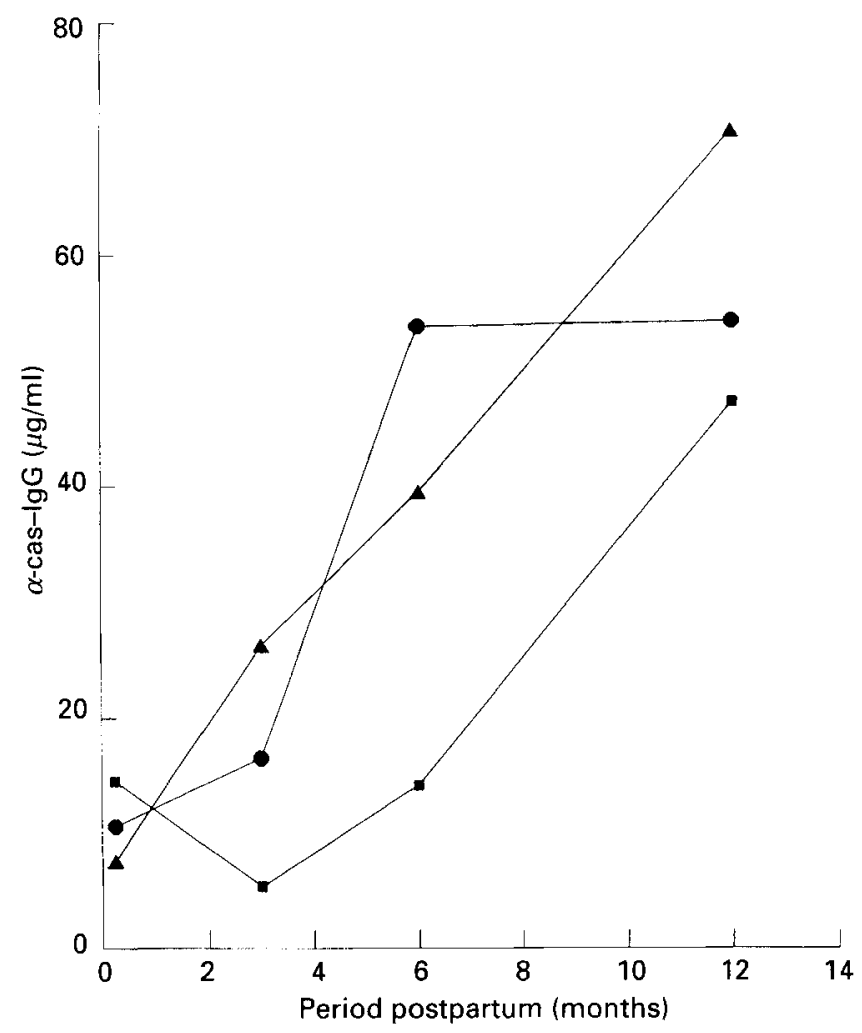

Fig. 3. Mean $\alpha$-casein ( $\alpha$-cas)-immunoglobulin $\mathrm{G}$ (IgG) antibody levels in serum samples from infants born to women in the atopic $(\mathbf{O})(n$ 14), non-atopic $(\mathbf{A})(n$ 13) and atopic-diet $(\boldsymbol{\square})(n$ 12) groups during the 12-month period postpartum. The mean SD was $140 \%$ of the mean (71-294\%). For details of subjects and procedures, see pp. 224-226 and Table 1.

The quantities of $\beta$ - $\mathrm{Lg}$ detected in the serum of women in the atopic-diet group before dietary restriction and the atopic women following an unrestricted diet were $2 \cdot 18$ (SD 2.14) and 1.93 (SD 2.58) $\mathrm{ng} / \mathrm{ml}$ respectively. These levels were comparable. No detectable $\beta$ - $\mathrm{Lg}$ was observed in the serum of subjects in the atopic-diet group who had strictly adhered to their milk-free diet, and even when a level of non-compliance was reported, with some ingestion of milk protein, the quantity of $\beta$ - $\mathrm{Lg}$ in the serum samples of these subjects was lower, when compared with their prediet levels.

\section{Infant serum samples}

The levels of $\beta$-Lg-IgG and $\alpha$-cas-IgG antibody levels in infant serum samples over a 12 month period are shown graphically in Figs 2 and 3 respectively. A higher, although not statistically significant, $\beta$-Lg-IgG antibody level compared with $\alpha$-cas-IgG antibody level was seen in the serum samples of the three groups, and these levels were significantly correlated $(r 0.89 P<0.0001)$.

No significant variation with time between groups or groups with time was found using a mixed-model analysis of variance for the 1-year-old infant serum samples. However, it was observed that the infants born to the women in the atopic group showed a dramatic increase in $\beta$ - $\mathrm{Lg}-\mathrm{IgG}$ and $\alpha$-cas-IgG antibody levels at 6 months which was seen to drop to values comparable with the other two groups by 12 months. The levels of $\beta-\operatorname{Lg}-\operatorname{IgG}$ and 
Table 4. $\beta$-lactoglobulin $(\beta$ - Lg)-immunoglobulin $A(\operatorname{Ig} A)$ and $\alpha$-casein $(\alpha$-cas)-IgA antibody levels in saliva samples of women in the atopic, non-atopic and atopic-diet group (approximately 36 weeks gestation) $\dagger$

(Mean values, standard deviations and ranges)

\begin{tabular}{|c|c|c|c|c|c|c|c|c|c|}
\hline \multirow[t]{2}{*}{$\begin{array}{l}\text { Study group ... } \\
n \ldots\end{array}$} & \multicolumn{3}{|c|}{$\begin{array}{c}\text { Atopic } \\
14\end{array}$} & \multicolumn{3}{|c|}{$\begin{array}{c}\text { Non-atopic } \\
12\end{array}$} & \multicolumn{3}{|c|}{$\begin{array}{c}\text { Atopic-diet } \\
12\end{array}$} \\
\hline & Mean & SD & Range & Mean & $\mathrm{SD}$ & Range & Mean & SD & Range \\
\hline$\beta-\mathrm{Lg}-\mathrm{IgA}(\mathrm{U} / \mathrm{ml})$ & $2 \cdot 8$ & $2 \cdot 6$ & nd -7.7 & $5 \cdot 6$ & $13 \cdot 3$ & nd $-45 \cdot 4$ & $3 \cdot 2$ & $2 \cdot 8$ & nd $-128 \cdot 7$ \\
\hline$\alpha$-cas- $\operatorname{IgA}(\mathrm{U} / \mathrm{ml})$ & $25 \cdot 6^{*}$ & $26 \cdot 3$ & $2 \cdot 3-87 \cdot 2$ & $34 \cdot 2^{*}$ & $18 \cdot 8$ & nd $-60 \cdot 0$ & $75 \cdot 1^{*}$ & $115 \cdot 0$ & $5 \cdot 4-410 \cdot 5$ \\
\hline
\end{tabular}

$\mathrm{U}$, arbitrary units based on a standard saliva sample; nd, not detected.

Mean values were significantly different from those for $\beta$ - $\mathrm{Lg}-\operatorname{IgA}:{ }^{*} P<0 \cdot 05$.

$\uparrow$ For details of subjects and procedures, see pp. 224-226 and Table 1.

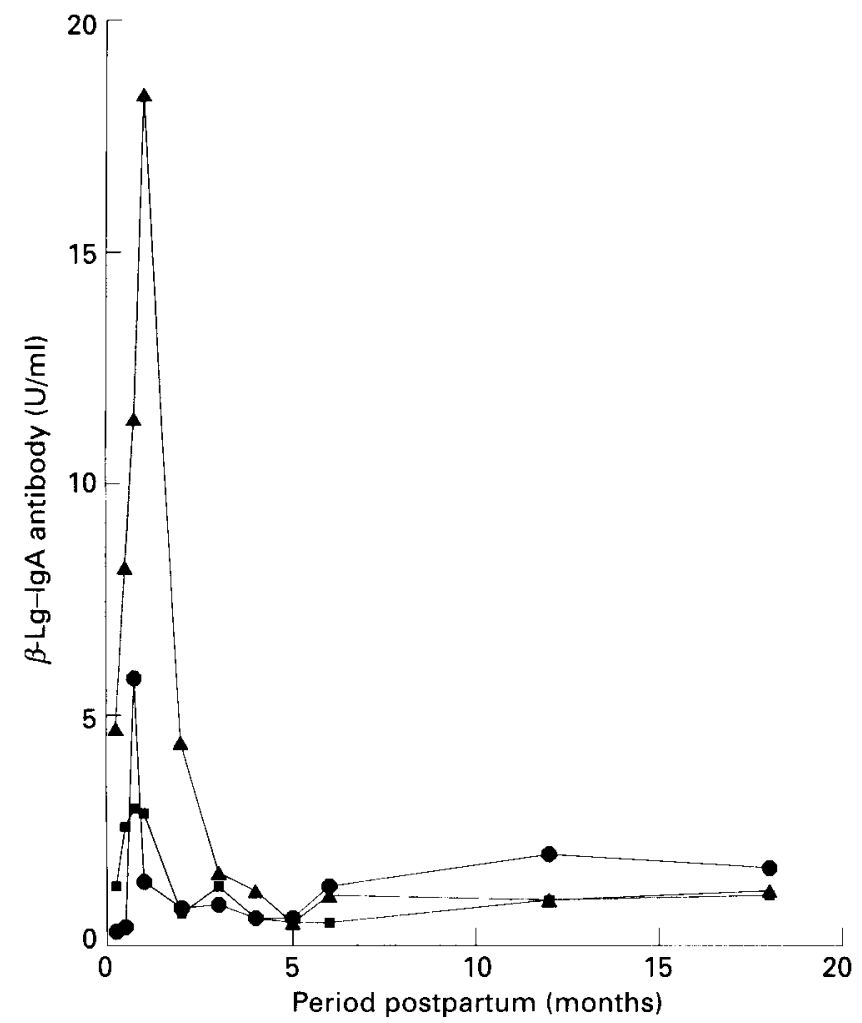

Fig. 4. Mean $\beta$-lactoglobulin $(\beta$-Lg)-immunoglobulin A (IgA) antibody leveis in saliva samples from infants born to women in the atopic $(\mathbf{O})(n$ 14), non-atopic $(\mathbf{A})(n$ 13) and atopic-diet $(\boldsymbol{\square})(n$ 12) groups during the 18-month period postpartum. The mean SD was $165 \%$ of the mean $(87-260 \%)$. For details of subjects and procedures, see pp. 224-226 and Table 1.

$\alpha$-cas-IgG antibodies in the infants born to the atopic mothers on the milk-restricted diet had the lowest mean antibody levels.

The $\beta$ - $\mathrm{Lg}-\mathrm{IgG}$ and $\alpha$-cas-IgG antibody levels were found to increase dramatically after the introduction of cow's milk into the infants' diet. The $\beta$-Lg-IgG antibody levels before and after the introduction of cow's milk were 25.2 (SD 23.6) and 235.2 (SD 200.7) $\mu \mathrm{g} / \mathrm{ml}$ 


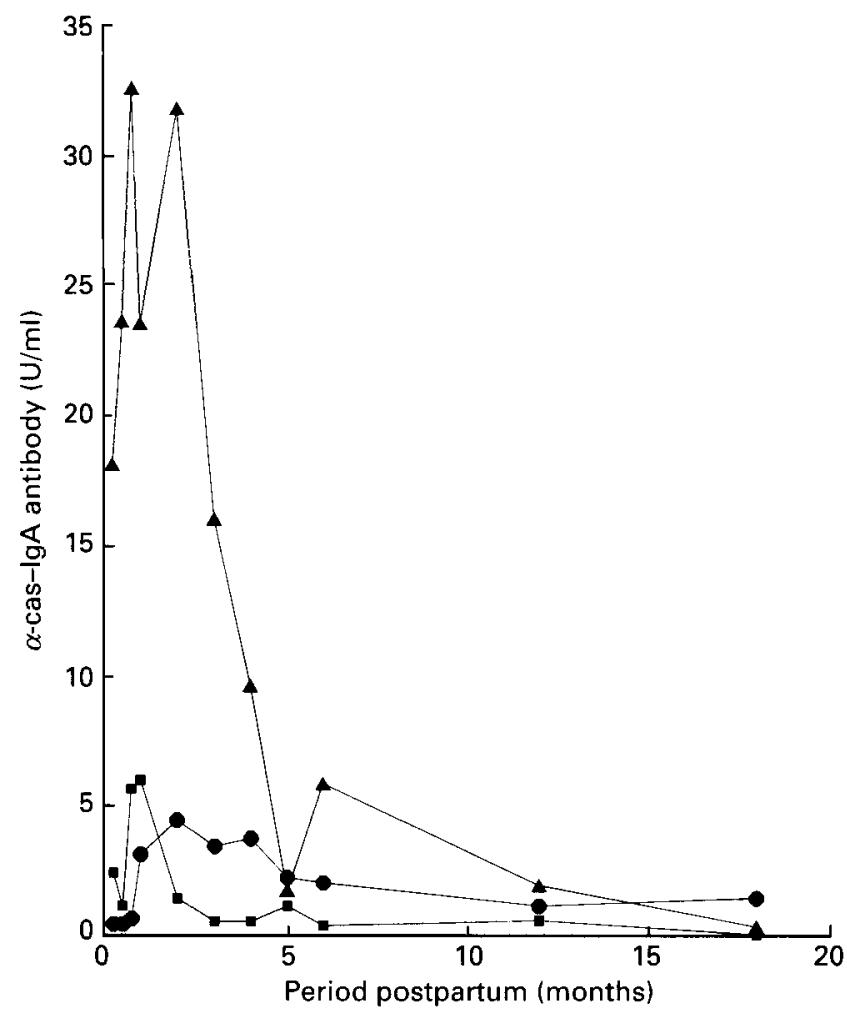

Fig. 5. Mean $\alpha$-casein ( $\alpha$-cas)-immunoglobulin A (IgA) antibody levels in saliva samples from infants born to women in the atopic $(\mathbf{O})(n$ 14), non-atopic $(\boldsymbol{A})(n$ 13) and atopic diet $(\boldsymbol{\square})(n$ 12) groups during the 18-month period postpartum. The mean SD was $174 \%$ of the mean (14-300\%). For details of subjects and procedures, see pp. 224-226 of proof and Table 1.

respectively, and the $\alpha$-cas-IgG antibody levels before and after were $7 \cdot 7$ (SD $9 \cdot 7$ ) and 53.7 (SD 54.9$) \mu \mathrm{g} / \mathrm{ml}$ respectively. After performing a paired Student's $t$ test the levels were found to increase significantly for both $\beta$-Lg-IgG antibody levels $(P<0.01)$ and $\alpha$-cas-IgG antibody levels $(P<0.05)$.

\section{Saliva samples}

Table 4 shows the mean $\beta$-Lg-IgA and $\alpha$-cas-IgA antibody levels in the three groups of women. There was found to be a significantly higher $\alpha$-cas-IgA antibody level in all the saliva samples compared with the $\beta-\operatorname{Lg}-\operatorname{IgA}$ levels $(P<0 \cdot 05)$. However, it must be stressed that the two ELISA carried out were semi-quantitative and, therefore, it was inappropriate to compare the values directly. The mean levels of $\beta$-Lg-IgA antibodies were comparable between the three groups. However, the mean $\alpha$-cas-IgA antibody level found in the atopicdiet group, 75.1 (SD 115.0; range 5.4410 .5 ) U/ml (arbitrary units based on a standard saliva sample), was found to be over $100 \%$ higher than the levels in the atopic group 25.6 (SD 26.3; range 2.3-87.2) $\mathrm{U} / \mathrm{ml}$ and non-atopic group $34.2(18.8$; range $0-60.0) \mathrm{U} / \mathrm{ml}$. On further examination of the individual values it was observed that one individual in the atopic-diet group had a level of $410.5 \mathrm{U} \alpha$-cas-IgA antibody $/ \mathrm{ml}$ in her saliva. When this value was excluded the mean $\alpha$-cas-IgA antibody level for the atopic-diet group was 44.6 (SD 29.0; range $5 \cdot 4-100 \cdot 0 \mathrm{U} / \mathrm{ml}$ ).

Figs 4 and 5 illustrate the $\beta$ - $\mathrm{Lg}-\operatorname{IgA}$ and $\alpha$-cas-IgA antibody levels in the infant saliva samples over an 18 -month period postpartum. No significant variation with time or 
differences between the three groups was observed for the $\beta-\operatorname{Lg}-\operatorname{IgA}$ and $\alpha$-cas- $\operatorname{IgA}$ antibody levels. However, a significant difference $(P<0.05)$ was observed for the variation of the non-atopic group with time. It was observed that the mean $\beta-\operatorname{Lg}-\operatorname{Ig} A$ and $\alpha$-cas $-\operatorname{IgA}$ antibody levels in the non-atopic group were higher between week 2 and month 2 . The levels were then found to fall dramatically and reach comparable levels with the other two groups by 12 months. All the groups showed an antibody peak at 1-2 months with levels then falling, reaching a plateau at 6 months.

\section{DISCUSSION}

Modification of the maternal diet during pregnancy and early lactation has been suggested as a means of preventing perinatal sensitization (Hamburger et al. 1983; Chandra et al. 1988) or inducing tolerance in the fetus and newborn (Pathirana et al. 1981; Notley et al. 1984; Telemo et al. 1987). In the present prospective randomized pilot study it was observed that there was an obvious hereditary influence in allergy incidence seen between the infants born to women in the atopic group following an unrestricted diet compared with women in the non-atopic group following an unrestricted diet. Although no firm conclusions could be drawn from the present study because of the small sample size, the data did indicate that there was a definite trend towards a lower allergy incidence in those infants born to atopic parents who were on the restricted diet compared with infants born to atopic parents on an unrestricted diet, indicating the necessity for further research.

Maternal dietary restriction of any kind is a laborious procedure for a pregnant woman. The timing of the diet for maximal benefit to the infant and minimal inconvenience to the mother is necessary. Previous studies have reported that maternal dietary restrictions during late pregnancy alone had no significant effect on infant allergy development (FälthMagnusson \& Kjellman, 1987; Fälth-Magnusson et al. 1987; Lilja et al. 1988, 1989), but was of benefit during lactation (Chandra et al. 1989; Hattevig et al. 1989, 1990) or during both late pregnancy and lactation (Chandra et al. 1986; Zeiger et al. 1989). It was thought important in the present study that the mother commenced any dietary restriction during late pregnancy in order for her to become accustomed to the diet, for absolute clearance of circulating milk antigens from her blood and to reduce the risk of an inadvertent intake of cows' milk protein during the more important lactation period.

The presence of antigenically-active $\beta$-Lg antigen in the maternal serum corresponded well with the occasions of known maternal dietary non-compliance. It was observed that the serum $\beta$ - $\mathrm{Lg}-\mathrm{IgG}$ and $\alpha$-cas-IgG antibody levels were reduced, significantly for $\beta$ $\mathrm{Lg}-\mathrm{IgG}$, after a period of 7 weeks dietary compliance, and continued to fall if the mother remained on the restricted diet, which has also been reported by Fälth-Magnusson et al. (1987) and Lilja et al. (1988).

The whey-hydrolysate infant formula, Peptijunior, was used and well tolerated by $37 \%$ of the women in the intervention group and the same proportion of infants. None of the infants who routinely ingested Peptijunior had developed allergies by 18 months. Allergic manifestations, however, were observed in the three infants who were inadvertently given cows' milk. The limited findings from the present study suggest the use of this formula could potentially be of benefit to the at-risk infant.

A significant correlation was observed between the $\beta$ - Lg-IgG and $\alpha$-cas-IgG antibody levels in the maternal, cord and infant serum samples. This indicates a heterogeneity in IgG synthesis, with 'high and low responders', and is in agreement with earlier studies (Dannaeus et al. 1977, 1978; Lilja et al. 1988). Another explanation for the large individual variation in circulating milk-specific antibody levels is the lack of standardization of the blood samples in relation to the last meal taken. This could lead to varying degrees of 
antibody neutralization by the absorbed food antigens (Lilja et al. 1988). However, this probably did not have a compounding effect as the antibody levels of the blood samples taken from the women on the milk-free diet showed a similar trend of wide variation.

It has been reported that atopic women have higher food $\mathrm{IgG}$ antibodies compared with non-atopic subjects (Fälth-Magnusson \& Kjellman, 1987; Fälth-Magnusson et al. 1987, 1988), and that atopic women seem to transfer larger amounts of milk and egg antibodies to the fetus compared with non-atopic women (Dannaeus et al. 1978). However, our results did not support these findings, with the non-atopic group having higher mean maternal and cord serum $\alpha$-cas $-\operatorname{IgG}$ antibody levels compared with the two atopic groups. High levels of IgG antibodies to food allergens have been suggested to afford protection against the development of atopic symptoms during the first 2 years of life (Casimir et al. 1985), although their predictive capacity with respect to atopic disease was not found to be convincing in this or other studies (Dannaeus et al. 1978; Fälth-Magnusson et al. 1988). A tendency to higher levels of milk-specific IgG antibodies in children who were considered to suffer from atopic disease was noted at 18 months of age in the present study and the study by Fälth-Magnusson et al. (1988).

The transfer of IgG antibodies via the placenta has been demonstrated in a number of studies (Kohler \& Farr, 1966; Carlsson et al. 1976; Fälth-Magnusson et al. 1988; Lilja et al. 1988). The correlation between the milk-specific IgG antibody levels in the maternal and cord serum samples, in addition to the higher cord serum milk-specific antibody levels, supports an active transport mechanism of these antibodies from mother to fetus. This transfer offers passive protection to the newborn infant for the first few months of life, and until the fetus becomes immunocompetent. No significant difference was observed between the 1-week-old infant serum samples and the cord serum samples, although the infant samples were higher. This, and the very close correlation of the $\beta$ - $\mathrm{Lg}$ - and $\alpha$-cas-specific IgG antibody levels in the cord and infant serum samples, supports the theory that the cord serum IgG antibodies are maternally derived.

The immunological influence of maternally-transferred milk-specific antibodies and milk antigens, to the fetus and infant was considered in the present study. Infant IgG antibody development over a 12-month period postnatally was investigated. No significant difference in the $\beta$-Lg-and $\alpha$-cas-specific IgG levels in the serum samples was observed between the three groups. This was also found by Hattevig et al. (1990) who were investigating the immune development of infants born to atopic and non-atopic women, following either an unrestricted diet or a milk-, egg- and fish-free diet during lactation. No significant difference in the IgG antibodies to ovalbumin or $\beta$ - $\mathrm{Lg}$ was detected between the groups of infants. Fälth-Magnusson et al. (1988) also reported no significant difference in the $\beta$-Lg-IgG antibody levels in infants born to mothers following a milk-free diet during pregnancy and lactation, although the babies from the allergen-free group were reported to have higher levels of IgG, IgA and IgM to ovalbumin and gliadin. The gradual increase in the levels of both the $\beta$-Lg-and $\alpha$-cas-specific IgG antibody levels observed in all three groups in the study may reflect the overall increase in total plasma IgG levels with age (May et al. 1977), although differences in the profiles of the three groups were seen.

The infants born to the atopic mothers following an unrestricted diet showed a dramatic increase in $\beta$ - $\mathrm{Lg}-\mathrm{IgG}$ and $\alpha$-cas-IgG antibody levels at 6 months, which fell to concentrations comparable with the other two groups by 12 months. Infants born to the atopic women on the milk-free diet and to the non-atopic women showed a more gradual increase in $\beta$ - $\mathrm{Lg}-\mathrm{IgG}$ and $\alpha$-cas-IgG antibody levels, which were found to be highest at 12 months postpartum. Infant $\beta$ - Lg-IgG and $\alpha$-cas-IgG serum antibody levels significantly increased after the ingestion of cows' milk for the first time, which has also been reported by Zieger et al. (1989) and Hattevig et al. (1990). It could be speculated that the observed 
trend of a higher milk-specific IgG antibody response at 6 months by the infants born to the atopic women reflected an earlier introduction of cows' milk into the infant's diet. This is not a plausible explanation, however, as the mean time of the introduction of cows' milk into the diet of the atopic-infant group was at a later time compared with the non-atopic group.

On further examination of the data, the trend for a higher IgG response against milk antigens by the infants born to the atopic mothers was also compounded by a tendency for those mothers to transfer more antigenically-intact $\beta$ - $\mathrm{Lg}$ via the placenta and to have lower $\beta$-Lg-and $\alpha$-cas-specific IgA antibody levels in their breast-milk samples (J. A. Lovegrove, J. B. Morgan and S. M. Hampton, unpublished results). The placental transfer of food antigens does occur in non-atopic mothers causing no detrimental effects in the majority of infants. Antigen exposure via breast milk did not differ between mothers feeding eczematous babies and non-eczematous babies (Cant et al. 1985). Further, the presence and quantity of $\beta$ - $\mathrm{Lg}$ was unrelated to antibody levels, infantile allergy symptoms and maternal atopic history (Machtinger \& Moss, 1986). Therefore, it could be suggested speculatively that a genetic predisposition could have significant influence on the infant's immune reaction to the ingested food proteins.

The salivary immune response was also monitored in the three groups of infants over an 18 -month period postnatally. $\beta$ - $\mathrm{Lg}-\operatorname{IgA}$ and $\alpha$-cas-IgA antibodies were detected in $45 \%$ of the 1-week-old infant saliva samples. Although adult levels of salivary IgA antibody are not reached until approximately 6 years of age (D'Amelio et al. 1986), evidence suggests that early salivary IgA production is common (Mellander et al. 1984; Frick \& Reiger, 1987; Cripps et al. 1989; Archibalds et al. 1990; Renz et al. 1990). Contamination of the saliva samples with breast milk could explain these initial high levels of $\operatorname{IgA}$ antibody within the saliva. However, in the present study care was taken to reduce such contamination of the saliva samples by collecting saliva at least $2 \mathrm{~h}$ after breast-feeding. It is recognized that mouth clearance may not be optimum in infants at an early age; however, high infant IgA antibody levels in saliva collected before the commencement of breast-feeding has been reported by Renz et al. (1990). The presence of IgA antibodies in saliva collected before the commencement of breast-feeding suggests that the antibodies were derived from the infant and not of maternal origin. It was observed that although there were no significant differences in the $\beta$-Lg- and $\alpha$-cas-specific IgA antibody levels between the three groups the infants in the non-atopic group had higher mean IgA antibody levels at 1-2 months, which dropped to levels comparable to the other two groups by 12 months. This was in contrast to Renz et al. (1990) who reported significantly elevated $\beta$-Lg-specific IgA and $\alpha$-casspecific IgA levels in infants in the 'high risk' group. However, the results presented here regarding the peak of milk-specific $\operatorname{IgA}$ antibody levels at about 1 month postpartum, and the gradual decline by 18 months was also reported by other groups (Mellander et al. 1984; Cripps et al. 1989; Renz et al. 1990).

\section{Summary}

In the present study parental atopy was found to have a significant influence on the allergy development in infants born to mothers following an unrestricted diet. A number of other groups have reported this, which reinforces the theory that infants with atopic parents have a genetic predisposition to allergy development. It was also observed that the allergy incidence of the infants whose mothers followed a strict milk-free diet during late pregnancy and lactation was comparable with that of the non-atopic group and significantly lower than that of the atopic group at 18 months postnatally (this was after the exclusion of three of the infants who had received a cows' milk formula within their first week of life due to unavoidable circumstances). This indicates a trend towards the beneficial effect of 
a maternal milk-free diet during late pregnancy and lactation on the allergy incidence in atrisk infants.

The authors would like to thank Cow \& Gate, Trowbridge, Wilts for their generous support of J.A.L. and this work and for the provision of Peptijunior. They are also very grateful to Dr Mir for his assistance in the allergy assessment of the infants. They would also like to acknowledge Dr Martin Crowder for his assistance with the statistics. Last, they would like to thank all the subjects and their babies for their cooperation in the study, without which this research would not have been possible.

\section{REFERENCES}

Aberg, N., Engstrom, I. \& Lindberg, U. (1989). Allergic diseases in Swedish school children. Acta Paediatrica Scandinavica 78, 246-252.

Archibald, D. W., Johnson, J. P., Nair, P., Alger, L. S., Hebert, C. A., Davis, E. \& Hines, S. E. (1990). Detection of salivary immunoglobulin A antibodies to HIV-l in infants and children. Aids 4, 417-420.

Cant, A. J., Marsden, R. A. \& Kilshaw, P. J. (1985). Egg and cow's milk hypersensitivity in exclusively breast fed infants with eczema, and the detection of egg protein in breast milk. British Medical Journal 291, 932-935.

Carlsson, B., Gothefors, L., Ahlstedt, S., Hanson, L. A. \& Winberg, J. (1976). Studies of E. coli O antigen specific antibodies in human milk, maternal serum and cord blood. Acta Paediatrica Scandinavica 65, $216-224$.

Casimir, G., Gossart, B., Vis, H. L. \& Duchateau, J. (1985). Antibody against betalactoglobulin (IgG) and cow's milk allergy. Journal of Allergy and Clinical Immunology 75, 206-207.

Chandra, R. K. (1988). Nutrition and immunity. Recenti Progressi in Medicina 79, 305-309.

Chandra, R. K., Puri, S. \& Hamed, A. (1989). Influence of maternal diet during lactation and the use of formula feeds on development of atopic eczema in high risk infants. British Medical Journal 299, 228-230.

Chandra, R. K., Puri, S., Suraiya, P. \& Cheema, P. S. (1986). Influence of maternal food antigen avoidance during pregnancy and lactation on incidence of atopic eczema in infants. Clinical Allergy 16, 563-569.

Cripps, A. W., Gleeson, M. \& Clancy, R. L. (1989). Molecular characteristics of IgA in infant saliva. Scandinavian Journal of Immunology 29, 317-324.

D’Amelio, R., Bonomo, R., D’Offizi, G. P., Mezzaroma, I., Pontesilli, O., Le Moli, S., Di Lollo, G. C., Mei, V., Pesce, G., Tanturli, E., Carlizza, L. \& Aiuti, F. (1986). Salivary Ig A levels in normal children. Diagnostic Immunology 4, 145-148.

Dannaeus, A., Johnsson, S. G. O. \& Foucard, T. (1977). Clinical and immunological aspects of food allergy in childhood. 1. Estimation of IgG, IgA and IgE antibodies to food antigens in children with food allergy and atopic dermatitis. Acta Paediatrica Scandinavica 66, 31-37.

Dannaeus, A., Johansson, S. G. O. \& Foucard, T. (1978). Clinical and immunological aspects of food allergy in childhood. II. Development of allergic symptoms and humoral immune response to food in infants of atopic mothers during the first 24 months of life. Acta Paediatrica Scandinavica 67, 497-504.

Department of Health (1991). Dietary Reference Values for Food Energy and Nutrients for the United Kingdom. Technical Series no. 4l. London: H.M. Stationery Office.

Fälth-Magnusson, K. \& Kjellman, N.-I. M. (1987). Development of atopic disease in babies whose mothers were receiving exclusion diets during pregnancy - a randomized study. Journal of Allergy and Clinical Immunology 80, 869-875.

Fälth-Magnusson, K., Kjellman, N.-I. M. \& Magnusson, K.-E. (1988). Antibodies IgG, IgA, and IgM to food antigens during the first 18 months of life in relation to feeding and development of atopic disease. Journal of Allergy and Clinical Immunology 81, 743-749.

Fälth-Magnusson, I., Oman, H. \& Kjellman, N.-I. M. (1987). Maternal abstention from cow milk and egg in allergy risk pregnancies. Allergy 42, $64-73$.

Frick, M. \& Rieger, C. H. L. (1987). Local antibodies $\alpha$-casein and $\beta$-lactoglobulin in the saliva of infants. Pediatric Research 22, 399. 401.

Hamburger, R. N., Hellers, S., Mellon, M. H., O'Connor, R. \& Zeiger, R. S. (1983). Current status of clinical and immunologic consequences of prototype allergic disease prevention programs. Annals of Allergy 51, 281-290.

Hampton, S. M., Morgan, J. B., Smith, M. R., Morris, R., Lovegrove, J. A. \& Marks, V. (1989). Circulating and secretory antibodies to specific food proteins in adults. Europern Joumal of Clinical Nutrition 44, 151-156.

Hattevig, G., Kjellman, B., Sigurs, N., Bjorksten, B. \& Kjellman, N.-I. M. (1989). Effect of maternal avoidance of eggs, cow's milk and fish during lactation upon allergic manifestations in infants. Clinical and Experimental Allergy 19, 27-32

Hattevig, G., Kjellman, B., Sigurs, N., Grodzinsky, E., Hed, J. \& Bjorksten, B. (1990). The effect of maternal avoidance of eggs, cow's milk, and fish during lactation on the development of $\operatorname{IgE} \operatorname{IgG}$, and $\operatorname{lgA}$ antibodies in infants. Joumal of Allergy and Clinical Immunology 85, 108-115. 
Jakobsson, I. \& Lindberg, T. (1978). Cow's milk as a cause of infantile colic in brest fed infants. Lancet ii, 437.

Kohler, P. F. \& Farr, R. S. (1966). Elevation of cord over maternal IgG immunoglobulins - evidence for an active placental IgG transport. Nature 210, 1070-1071.

Lilja, G., Dannaeus, A., Fälth-Magnusson, K., Graff-Lonnevig, V., Johnsson, S. G. O., Kjellman, N.-I. M. \& Oman, H. (1988). Immune response of the atopic women and foetus: effect of high-and low-dose food allergen intake during late pregnancy. Clinical Allergy 18, 131-142.

Lilja, G., Dannaeus, A., Foucard, T., Graff-Lonnevig, V., Johansson, S. G. O. \& Oman, H. (1989). Effects of maternal diet during late pregnancy and lactation on the development of atopic diseases in infants up to 18 months of age - in vivo results. Clinical and Experimental Allergy 19, 473-479.

Lovegrove, J. A. (1991). Studies of milk antibodies and antigens in human adults and infants. PhD Thesis, University of Surrey.

Lovegrove, J. A., Hampton, S. M., Morgan, J. B. \& Marks, V. (1989). Quantification of total IgG levels against $\alpha$-casein in human serum samples serum. Biochemical Society Transactions 17, 1059-1060.

Lovegrove, J. A., Osman, D. L., Morgan, J. B. \& Hampton, S. M. (1993). The transfer of cow's milk $\beta$ lactoglobulin to human serum after a milk load: a pilot study. Gut 34, 203-207.

Machtinger, S. \& Moss, R. (1986). Cow's milk allergy in breast fed infants: the role of allergen and maternal secretory IgA antibody. Journal of Allergy and Clinical Immunology 77, 341.

May, C. D., Remigio, L., Feldman, J., Bock, S. H. \& Carr, R. I. (1977). The study of serum antibodies to isolated milk proteins and ovalbumin in infants and children. Clinical Allergy 7, 583-595.

Mellander, L., Carlsson, B. \& Hanson, L. A. (1984). Appearance of secretory IgM and IgA antibodies to E. coli in saliva during early infancy and childhood. Journal of Pediatrics 104, 564-568.

Notley, J. R., Gibney, M. J. \& Gallagher, P. J. (1984). Absence of an effect of tolerance to milk protein on experimental atherosclerosis in rabbits. Atherosclerosis 52, 199-202.

Pathirana, C., Goulding, N. J., Gibney, M. J., Pitts, J. M., Gallagher, P. J. \& Taylor, T. G. (1981). Immune tolerance produced by pre- and postnatal exposure to dietary antigens. International Archives of Allergy and Applied Immunology 66, $114-118$.

Renz, H., Vestner, R., Petzoldt, S., Brehler, C., Prinz, H. \& Rieger, C. H. L. (1990). Elevated concentrations of salivary secretory immunoglobulin A anti-cow's milk protein in newborns at risk of allergy. International Archives of Allergy and Applied Immunology 92, 247-253.

Sokal, R. R. \& Rohlf, F. J. (1969). Biometry. The principles and statistics in biological research, 1st ed. San Francisco: W. H. Freeman and Company.

Talbot, F. B. (1918). Eczema in childhood. Medical Clinics of North America 1, 985.

Telemo, E., Jakobsson, I., Weström, B. R. \& Folkesson, H. (1987). Maternal dietary antigens and the immune response in the offspring of the guinea-pig. Immunology 62, 35-38.

Zeiger, R. S., Heller, S., Mellon, M. H., Forsythe, A. B., O'Connor, R. D., Hamburger, R. N. \& Schatz, M. (1989). Effect of combined maternal and infant food-allergen avoidance on the development of atopy in early infancy: a randomized study. Journal of Allergy and Clinical Immunology 84, 72-89. 